\title{
Nilai Total Flavonoid dalam Black Garlic (Allium sativum L.) Berdasarkan Fraksi Pelarut dan Aktivitas Antioksidan
}

\section{Value of Total Flavonoids in Black Garlic (Allium sativum L.) Based on The Solvent Fraction and Antioxidant Activity}

\section{Gladys Ayu Paramita Kusumah Wardhani1 ${ }^{*}$, Mia Azizah², Lisnawati Tri Hastuti ${ }^{3}$}

\author{
${ }^{1,3}$ Kimia, FMIPA, J1.Sholeh Iskandar, km.4, Tanah Sareal, Bogor, 16166, Indonesia \\ ${ }^{2}$ Biologi, FMIPA, Jl.Sholeh Iskandar, km.4, Tanah Sareal, Bogor, 16166, Indonesia \\ aKorespondensi : Gladys Ayu Paramita Kusumah Wardhani, Email: gladys.paramita@gmail.com
}

(Diterima oleh Dewan Redaksi : 23 - 10 - 2019)

(Dipublikasikan oleh Dewan Redaksi : 08 - 04 - 2020)

\begin{abstract}
Black garlic is a garlic that has been processed through a non-enzymatic browning reaction (Maillard reaction) at a certain temperature for a long time, thus producing new compounds which is as an antioxidant. The purpose of this study is to determine the total flavonoid content of the black garlic fraction (Allium Sativum L.) and its antioxidant activity. The first step is the total methanol extract, followed by fractionation method using water, dichloromethane and nhexane. Flavonoid compounds determine by the Wilstatter method. The analysis of total flavonoids by an external standard method using the UV-Vis spectrophotometer instrument. The last step is to test the antioxidant activity of fraction with highest total flavonoid using Quercetin standard. The results obtained were black garlic extract containing flavonoids. Dichloromethane extract had the highest total flavonoid value of $55.68 \mathrm{mg} \mathrm{QE} \mathrm{/} \mathrm{g} \mathrm{extract,}$ followed by water extract and n-hexane extract respectively 10.31 and $5.11 \mathrm{mg} \mathrm{QE} \mathrm{/} \mathrm{g} \mathrm{extract.}$ IC50 black garlic value in dichloromethane extract was $361.07 \mu \mathrm{g} / \mathrm{mL}$ so that it was classified as a compound with moderate levels of antioxidants.
\end{abstract}

Keywords: black garlic, flavonoid, antioxidant, dichloromethane

\begin{tabular}{l} 
ABSTRAK \\
Blackgarlic merupakan produk bawang putih hasil dari proses melalui reaksi pencoklatan non \\
enzimatis suhu tertentu dengan waktu lama, sehingga menghasilkan senyawa baru yang \\
mempunyai efek farmakologis, salah satunya sebagai antioksidan. Tujuan dari penelitian yang \\
dilakukan adalah menentukan kandungan total flavonoid dari fraksi black garlic serta \\
menentukan aktivitas antioksidannya pada fraksi dengan nilai total flavonoid yang tertinggi. \\
Tahap pertama adalah perolehan ekstrak metanol total, selanjutnya ekstraksi fraksinasi \\
menggunakan air, diklorometana dan n-heksana. Tahap kedua adalah uji kualitatif senyawa \\
flavonoid dengan metode Wilstatter. Tahap ketiga adalah analisis total flavonoid dengan \\
metode standar eksternal dengan instrumen Spektrofotometer UV-Vis. Tahap terakhir \\
standar Kuersetin untuk uji aktivitas antioksidan. Hasil yang diperoleh yaitu ekstrak black \\
garlic dalam air, diklorometana, dan n-heksana mengandung flavonoid. Ekstrak \\
diklorometana memiliki nilai total flavonoid paling besar yaitu 55,68 mg QE/g ekstrak, diikuti \\
oleh nilai total flavonoid ekstrak air dan ekstrak n-heksana masing-masing sebesar 10,31 dan \\
5,11 mg QE/g ekstrak. Nilai IC50 black garlic dalam ekstrak diklorometana sebesar 361,07 \\
mg/mL sehingga digolongkan sebagai senyawa dengan tingkat antioksidan yang sedang. \\
Kata Kunci: black garlic, flavonoid, antioksidan, diklorometana \\
\hline Wardhani, Gladys Ayu Paramita Kusumah, Mia Azizah, Lisnawati Tri Hastuti. 2020. Nilai Total \\
Flavonoid dalam Black Garlic (Allium sativum L.) Berdasarkan Fraksi Pelarut dan Aktivitas Antioksidan. \\
Jurnal Agroindustri Halal 6(1): 20 - 27
\end{tabular}




\section{PENDAHULUAN}

Black garlic adalah produk bawang putih yang telah difermentasi dalam jangka waktu tertentu pada suhu dan kelembaban tinggi (Cheng et al. 2016). Bawang ini memiliki banyak kelebihan diantaranya rasa buah yang ringan dan asam, tidak berbau pedas, bersifat hypoallergenic dan dapat digunakan terus - menerus dalam waktu yang lama tanpa ada efek samping (Ai dan Huong 2018). Beberapa orang mengkonsumsi black garlic dalam bentuk suplemen atau dimakan secara langsung. Hal ini untuk mendapatkan manfaat kesehatan dan juga dapat menikmati rasanya yang unik.

Black garlic sebagai rempah dan tumbuhan bumbu merupakan sumber antioksidan alami. Manfaat antioksidan alami dari rempah dan tumbuhan bumbu yaitu lebih mudah diasimilasikan ke dalam tubuh (Embuscado 2015).

Black garlic memiliki sifat antioksidan dua kali lebih banyak daripada bawang putih. Selain itu juga dapat bermanfaat sebagai antibakteri, antikarsinogenik, menurunkan tekanan darah tinggi, menurunkan kolesterol, mencegah obesitas, melawan diabetes, meregenerasi sel kulit, memperkuat sistem kekebalan tubuh, dan mengurangi alergi. Manfaat ini terkait dengan senyawa bioaktifnya yang dapat terbentuk selama perlakuan panas (Wu et al. 2018). Senyawa bioaktif tersebut diantaranya yakni S-allyl cysteine (SAC), asam amino, flavonoid, dan polifenol (Yuan et al. (2016) ; Handayani et al. 2018).

Flavonoid mudah diekstraksi dari berbagai tumbuhan. Menurut Liu (2011), kelarutan flavonoid ditentukan oleh struktur kimianya. Senyawa flavonoid diperkirakan akan tertarik ke dalam pelarut yang bersifat lebih polar.

Pada penelitian ini dilakukan studi mengenai nilai total flavonoid dari ekstrak metanol dan fraksi black dalam air, diklorometana, dan n-heksana serta ditentukan aktivitas antioksidannya pada fraksi black garlic dengan kandungan total flavonoid paling tinggi.

\section{MATERI DAN METODE}

\section{Bahan dan Alat}

Bahan-bahan yang digunakan adalah black garlic multi siung, metanol p.a., nheksana, diklorometana, akuades, etanol $80 \%$, serbuk $\mathrm{Mg}, \mathrm{HCl} 0,5 \mathrm{M}, \mathrm{NaNO}_{2} 5 \%$, $\mathrm{AlCl}_{3} \bullet 6 \mathrm{H}_{2} \mathrm{O} 10 \%$ dan $\mathrm{NaOH} 1 \mathrm{M}$, uap $\mathrm{NH}_{3}$, DPPH (1,1-difenil-2-pikrilhidrazil), dan standar kuersetin.

Peralatan yang digunakan dalam penelitian ini yaitu peralatan gelas, pisau, rotary evaporator, blender, vortex, magnetic stirrer, oven, neraca analitik, kain saring, dan instrumen spektrofotometer UV-VIS (Ultraviolet-Visibel) Genesys.

\section{Pembuatan Simplisia}

Black garlic dikupas dan dibersihkan untuk memisahkan kulitnya, selanjutnya dipotong kecil-kecil memanjang. Umbi black garlic yang telah dipotong kemudian diletakkan pada loyang datar dengan tumpukan setipis mungkin $( \pm 1 \mathrm{~cm})$, lalu dikeringkan dengan oven pada suhu $60^{\circ} \mathrm{C}$. Black garlic dioven hingga kering kemudian ditentukan nilai kadar airnya.

\section{Ekstraksi Black garlic}

Simplisia black garlic diekstraksi sebanyak $250 \mathrm{~g}$ dengan teknik maserasi menggunakan pelarut metanol : air (9:1). Penyaringan dilakukan setelah 1 hari, filtrat ditampung dalam botol. Filtrat hasil maserasi diuapkan sisa pelarutnya dengan rotary evaporator hingga menjadi ekstrak kental (maserat).

Maserat diekstraksi fraksinasi menggunakan corong pisah dengan campuran pelarut akuades : n-heksana (1: 1) sebanyak 3 kali. Filtrat air yang diperoleh selanjutnya diekstraksi kembali menggunakan diklorometana sebanyak 3 kali. Masing-masing filtrat hasil ekstraksi dievaporasi sehingga diperoleh ekstrak nheksana, ekstrak diklorometana dan ekstrak air. 


\section{Uji Fitokimia Flavonoid}

Maserat dan ekstrak hasil fraksinasi diuji fitokimia untuk mengetahui kandungan flavonoidnya dengan metode uji Wilstatter, caranya yaitu masing-masing ekstrak sejumlah $500 \mathrm{mg}$ ditambahkan 5 tetes etanol $80 \%$, kemudian diaduk hingga homogen dan selanjutnya ditambahkan $0,5 \mathrm{~g}$ magnesium dan $\mathrm{HCl}$ 0,5 M. Reaksi positif ditunjukan dengan terbentuknya perubahan warna larutan menjadi warna merah, kuning atau jingga.

\section{Penentuan Kadar Flavonoid Total}

Larutan sampel sebanyak $1 \mathrm{~mL}$ dimasukkan ke dalam vial yang sebelumnya sudah ditambahkan $4 \mathrm{~mL}$ aquades dan 0,3 mL larutan $\mathrm{NaNO}_{2} 5 \%$, dibiarkan selama 5 menit. Selanjutnya larutan ditambahkan dengan $0,3 \mathrm{~mL} \mathrm{AlCl} 3 \quad 10 \%$ dan dibiarkan selama 6 menit, kemudian larutan ditambahkan $2 \mathrm{~mL} \mathrm{NaOH} 1 \mathrm{M}$, dan 2,4 mL aquades, dihomogenkan menggunakan vortex. Setelah itu absorbansinya diukur pada $\lambda$ maks $510 \mathrm{~nm}$ dan dihitung nilai total flavonoidnya menggunakan standar eksternal kuersetin.

\section{Pengujian Aktivitas Antioksidan}

Ekstrak diklorometana dengan konsentrasi 100, 200, 300, 400, 500, 600, 700 dan $800 \mu \mathrm{g} / \mathrm{mL}$ diambil sebanyak $1 \mathrm{~mL}$, kemudian ditambahkan $2 \mathrm{~mL}$ DPPH 0,1 mM dalam tabung reaksi. Selanjutnya campuran tersebut dihomogenkan dan diinkubasi pada suhu kamar selama 30 menit ditempat gelap. Larutan ini selanjutnya diukur absorbansinya pada $\lambda$ maks $516 \mathrm{~nm}$ ( $\lambda$ maks ditentukan terlebih dahulu dengan scanning $\lambda$ pada rentang (400 - $800 \mathrm{~nm}$ ). Perlakuan yang sama juga dilakukan untuk larutan blanko (larutan DPPH• yang tidak mengandung bahan uji) dan kontrol positif kuersetin dengan konsentrasi dengan konsentrasi $1,2,3,4,5,6,7$, dan $8 \mu \mathrm{g} / \mathrm{mL}$. Data hasil pengukuran absorbansi ditentukan persentase aktivitas antioksidannya menggunakan persamaan berikut :
\% Hambatan Radikal Bebas =

$\frac{\text { Serapan blanko-Serapan sampel }}{\text { Serapan blanko }} \times 100 \%$

Setelah itu, nilai IC50 dari setiap ekstrak dapat diketahui menggunakan persamaan garis dengan konsentrasi ekstrak sebagai sumbu $\mathrm{x}$ dan persen hambatan sebagai sumbu $y$.

\section{HASIL DAN PEMBAHASAN}

\section{Kadar Air Simplisia Black garlic}

Black garlic yang digunakan dalam penelitian ini tidak didapatkan informasi pada suhu berapa dan berapa lama tahap agingnya. Black garlic memiliki warna hitam pekat dan tekstur yang kenyal dan lunak. Rasanya manis, asam dan sedikit pahit dengan aroma seperti bawang putih yang dimasak. Untuk membuat simplisia, black garlic perlu dipotong tipis memanjang dan kecil-kecil agar memudahkan proses pengeringannya. Semakin luas permukaan black garlic akan semakin cepat terjadinya proses pengeringan.

Rendemen black garlic yang diperoleh sebesar 68,62 \%. Kadar air yang diperoleh sebesar 8,87 \%. Kadar air perlu ditentukan untuk memenuhi syarat dalam pembuatan simplisia. Kadar air dalam pembuatan simplisia harus kurang dari $10 \%$. Semakin kecil kadar air akan memudahkan difusi pelarut yang akan menarik senyawa golongan flavonoid yang terkandung dalam black garlic (Saifudin 2012). Tinggi rendahnya kadar air black garlic tergantung dari tinggi rendahnya temperatur aging yang digunakan (Zhang et al. 2015; Zhafira 2018).

\section{Ekstrak Black garlic}

Black garlic dalam bentuk simplisia diekstraksi dengan dua cara yang pertama dengan maserasi dan ekstraksi fraksinasi. Esktraksi ini bertujuan untuk menarik senyawa flavonoid yang terkandung dalam black garlic. Simplisia black garlic yang dihasilkan sebanyak 250 gram dimaserasi pada suhu kamar menggunakan pelarut metanol : air (9:1) menghasilkan maserat yang berwarna hitam pekat. Dua mekanisme 
dasar pada tahap ekstraksi meliputi disolusi dan difusi (Saifudin 2012).

Disolusi pada tahap maserasi ini yaitu proses terendamnya senyawa flavonoid black garlic dalam pelarut metanol. Sedangkan difusi, terjadi saat terbawanya senyawa flavonoid tersebut oleh metanol keluar sel atau matriks black garlic. Meskipun metode maserasi ini memerlukan banyak waktu dan pelarut, namun dapat menghindari rusaknya senyawa-senyawa yang sensitif terhadap suhu tinggi (Mukhriani 2014) Semua flavonoid baik dalam bentuk glikosida maupun flavonoid dalam bentuk bebas dapat larut dalam pelarut methanol (Harborne 2007). Selain itu titik didih metanol mempunyai nilai yang cukup rendah $\left(64,5^{\circ} \mathrm{C}\right)$, sehingga lebih mudah untuk memisahkannya (Tanaya et al. 2015)

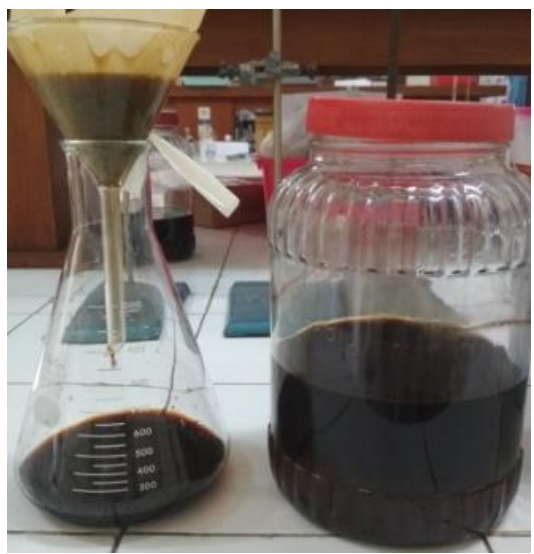

Gambar 1. Hasil maserasi (maserat) Black garlic

Maserat yang diperoleh (Gambar 1) dipekatkan menggunakan rotary evaporator untuk menguapkan metanol. Persen rendemen yang diperoleh 70,4\%. Maserat yang diperoleh, diekstrak menggunakan metode ekstraksi fraksinasi dengan pelarut air, diklorometana, dan n-heksana. Ekstrak dari masing - masing pelarut tersebut dipekatkan kembali menggunakan rotary evaporator untuk menguapkan pelarutnya agar tidak mengganggu proses pengujian selanjutnya.

Persen rendemen yang diperoleh yaitu: ekstrak n-heksana 0,256 \%, ekstrak diklorometana 0,224 \% dan ekstrak air 58,8\%. Pada ekstraksi fraksinasi, fraksi fraksi pelarut dapat terpisah berdasarkan tingkat polaritasnya.

Hasil yang diperoleh pada Gambar 2 menunjukkan ekstrak n-heksana, diklorometana, dan air pada black garlic. Ekstrak dalam n-heksan berwarna kuning keruh dan terbentuk gel, ekstrak diklorometan berwarna keemasan, sedangkan ekstrak air berwarna hitam pekat seperti maserat awal. Hasil ekstrak dengan warna yang berbeda ini, dipengaruhi oleh kelarutan flavonoid terhadap polaritas pelarut.

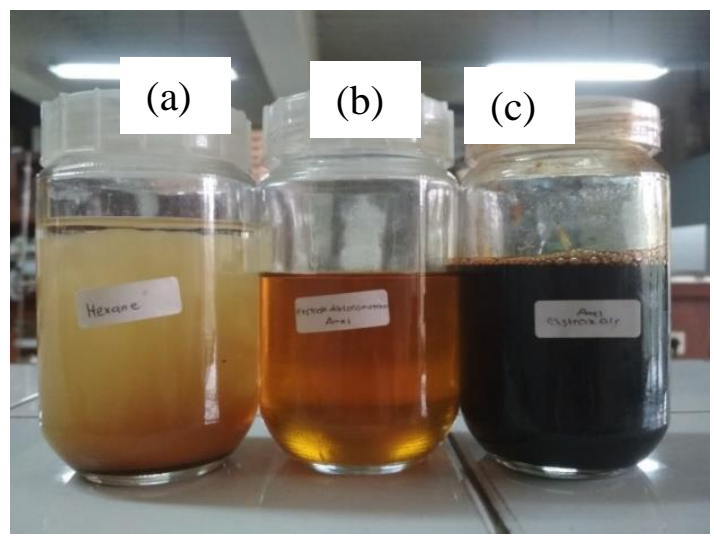

Gambar 2. Hasil ekstraksi fraksinasi black garlic (a) ekstrak n-heksana, (b) ekstrak diklorometana, dan (c) ekstrak air

Pelarut yang digunakan dalam ekstraksi fraksinasi pada penelitian ini memiliki tingkat kepolaran yang berbedabeda. Polaritas air > diklorometana > nheksana. Semakin polar pelarut yang digunakan untuk ekstraksi semakin gelap warna ekstrak yang dihasilkan. Kelarutan flavonoid dipengaruhi oleh bentuknya (Liu 2011). Flavonoid aglikon (flavonoid yang tidak mengikat gula) sedikit larut dalam air dan beberapa pelarut organik lainnya. Sedangkan flavonoid glikosida (flavonoid yang mengikat gula) mudah larut dalam air panas, metanol dan pelarut polar lainnya.

\section{Senyawa Flavonoid dalam Black garlic}

Senyawa flavonoid dapat ditentukan secara kualitatif dan kuantitatif. Secara kualitatif dapat ditentukan dengan skrining 
fitokimia flavonoid menggunakan metode Wilstatter. Hasil yang diperoleh pada Gambar 3 menunjukkan bahwa masing masing ekstrak positif mengandung senyawa golongan flavonoid. Hal ini diindikasikan dengan terbentuknya warna jingga pada larutan. Namun, intensitas warna jingga pada ketiga ekstrak berbeda.

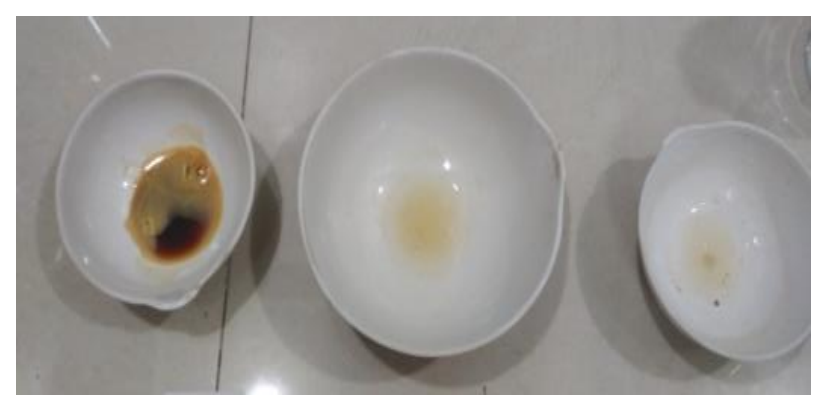

(a)

(b)

(c)

Gambar 3. Skrining Fitokimia Flavonoid Black garlic Ekstrak (a) Air, (b)

Diklorometana, dan (c) n-heksana

Penentuan kadar flavonoid secara kuantitatif dilakukan dengan metode standar eksternal menggunakan larutan standar kuersetin yang diukur absorbansinya pada panjang gelombang maksimum $510 \mathrm{~nm}$. Kuersetin merupakan tipe flavonol (struktur primer sebagai kuersetin glikosida) merupakan molekul flavonoid yang melimpah dan banyak terdistribusi dalam tanaman (Shah et al. 2016). Kuersetin memiliki gugus kromofor dan auksokrom pada strukturnya (Gambar 4).

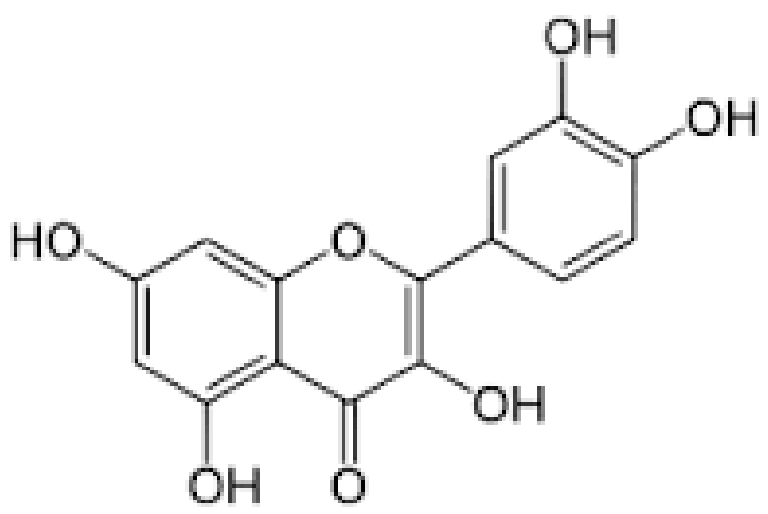

Gambar 4. Struktur Kimia Kuersetin
Total flavonoid yang dihitung dalam penelitian ini diasumsikan sebagai golongan flavonoid jenis flavonol karena menggunakan senyawa standar kuersetin. Nilai total flavonoid dinyatakan dalam mg QE/g ekstrak. Gambar 5 menunjukkan nilai total flavonoid masing-masing ekstrak.

Ekstrak diklorometana memiliki nilai total flavonoid paling besar yaitu 55,68 mg QE/g ekstrak, diikuti oleh nilai total flavonoid ekstrak air dan ekstrak n-heksana masing-masing sebesar 10,31 dan 5,11 mg QE/g ekstrak. Hal ini menunjukkan bahwa pelarut diklorometana merupakan pelarut yang paling baik dalam mengekstrak senyawa golongan flavonoid jenis flavonol yang ada dalam Black garlic. Black garlic memiliki nilai total flavonoid yang lebih tinggi daripada bawang putih segar karena terjadi reaksi Maillard (Choi et al. 2014).

\section{Aktivitas Antioksidan Black garlic}

Aktivitas antioksidan black garlic pada ekstrak diklorometana ditentukan untuk mengetahui seberapa besar kemampuan senyawa flavonoid yang terkandung di dalamnya mampu menghambat reaksi oksidasi. Penenetuan aktivitas antioksidan dilakukan menggunakan metode DPPH. Kontrol positif yang dipilih yaitu senyawa kuersetin.

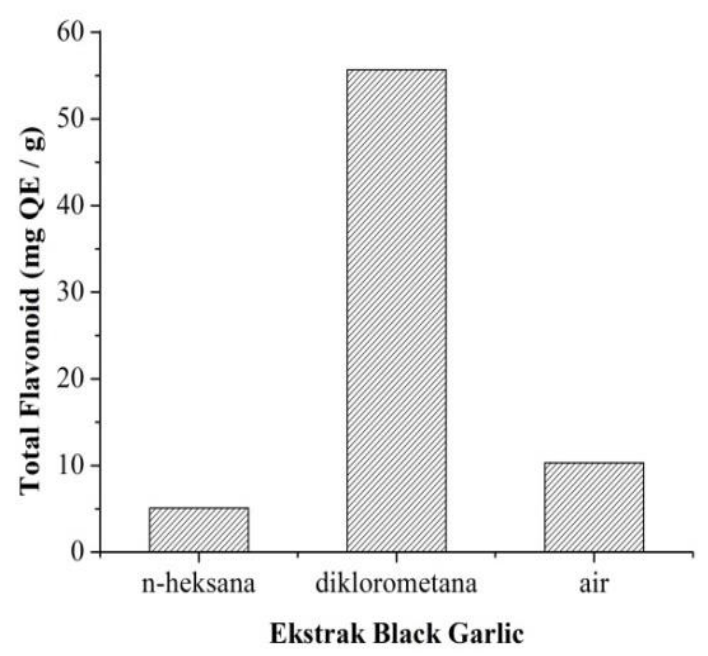

Gambar 5. Total flavonoid ekstrak black garlic dalam berbagai pelarut. 
Metode ini dipilih karena mudah dan cepat untuk menentukan aktivitas antioksidan. Metode DPPH ini lebih baik daripada metode ABTS dalam menentukan aktivitas antioksidan (Nassur et al. 2017). Radikal bebas DPPH berwarna ungu dan memiliki panjang gelombang maksimum $517 \mathrm{~nm}$. Hal ini sesuai dengan penelitian yang mendapatkan panjang gelombang maksimum radikal DPPH pada $517 \mathrm{~nm}$ (Nurcholis et al. 2017).

Ketika radikal DPPH ditambahkan ekstrak diklorometana, panjang gelombang maksimum muncul pada $517 \mathrm{~nm}$ dengan absorbansi yang semakin menurun. DPPH yang dicampur dengan zat yang dapat menyumbangkan atom hidrogen, akan menjadi bentuk tereduksi (Difenil pikril hidrazin: non radikal) sehingga menghilangkan warna violet dari radikal bebas DPPH dan membentuk warna kuning dari grup pikril (Sa'adah et al. 2017). Hal inilah yang menyebabkan pergeseran panjang gelombang maksimum tersebut.

Aktivitas antioksidan ini dinyatakan dalam \% inhibisi. Nilai inhibisi ini digunakan untuk menentukan nilai IC $_{50}$. Nilai IC $_{50}$ merupakan nilai yang menggambarkan konsentrasi ekstrak yang dapat menangkap radikal bebas sebesar 50\%. Semakin kecil nilai $\mathrm{IC}_{50}$ aktivitas antioksidannya semakin tinggi (Zuhra et al. 2008).

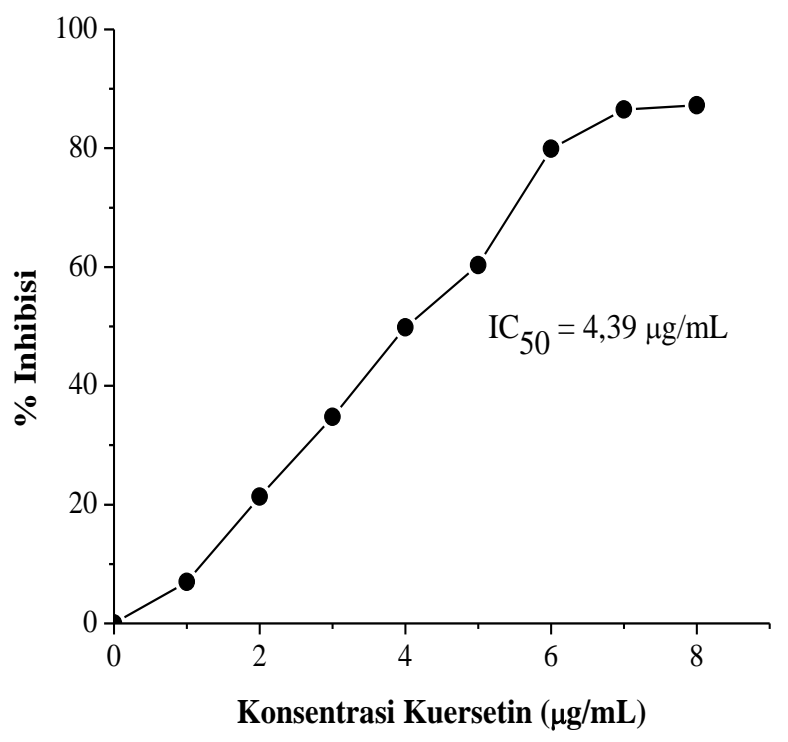

(a)

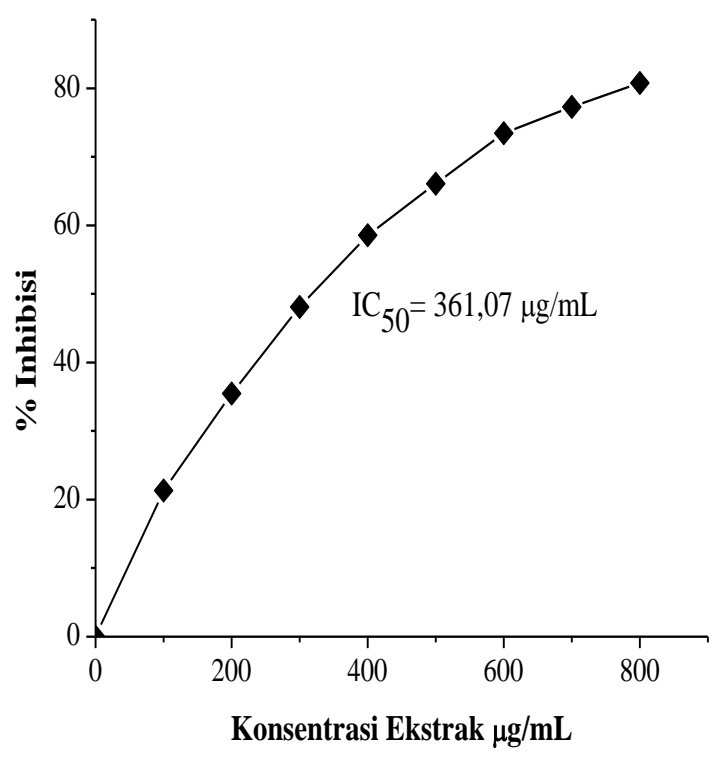

(b)

Gambar 6. Aktivitas inhibisi (a) kuersetin dan (b) black garlic dalam ekstrak diklorometana

Gambar 6 menunjukkan aktivitas inhibisi kuersetin dan black garlic dalam ekstrak diklorometana. Nilai IC50 kuersetin sebesar 4,23 $\mu \mathrm{g} / \mathrm{mL}$ sedangkan $\mathrm{IC}_{50}$ black garlic dalam ekstrak diklorometana sebesar 361,07 $\mu \mathrm{g} / \mathrm{mL}$. Aktivitas antioksidan berdasarkan nilai $\mathrm{IC}_{50}$ dibagi menjadi tiga golongan : (1) kuat dengan IC $50<100 \mu \mathrm{g} / \mathrm{mL}$ ; (2) sedang dengan IC50 $100-500 \mu \mathrm{g} / \mathrm{mL}$; dan (3) lemah dengan $\mathrm{IC}_{50}>500 \mu \mathrm{g} / \mathrm{mL}$ (Bi et al. 2016). Aktivitas antioksidan black garlic dalam ekstrak diklorometana termasuk ke dalam golongan antioksidan yang sedang.

\section{KESIMPULAN}

Black garlic dalam fraksi ekstrak diklorometana memiliki nilai total flavonoid paling tinggi daripada ekstrak air dan nheksana yaitu sebesar 55,68 mg QE/g. Nilai $\mathrm{IC}_{50}$ black garlic dalam ekstrak diklorometana sebesar 361,07 $\mu \mathrm{g} / \mathrm{mL}$ sehingga digolongkan sebagai senyawa dengan tingkat antioksidan yang sedang. 


\section{UCAPAN TERIMAKASIH}

Kami mengucapkan terimakasih kepada Kementrian Ristek-DIKTI yang telah memberikan dana penelitian dalam skema Penelitian Dosen Pemula (PDP).

\section{DAFTAR PUSTAKA}

Ai TT dan Huong NT. 2018. Research on the Production of Black Garlic Juice. International Journal of Pharmaceutical Science Invention. 7 (5).

Cheng KC, Kimura S, La YJ, Pan MS, Su N W, Tung, Y. C. 2016. Black Garlic: A Critical Review of Its Production, Bioactivity, and Application. Journal of Food and Drug Analysis. 25 (1): 62 - 70. https://doi.org/10.1016/j.jfda.2016.11.0 $\underline{03}$

Embuscado ME. 2015. Spices and Herbs: Natural Sources of Antioxidants - A Mini Review. J Funct. Foods. doi:10.1016/j.jff.2015.03.005.

Handayani SNUR, Bawono LC, Pramesti D, Pratiwi HN. 2018. Isolasi Senyawa Polifenol Black garlic dan Uji Toksisitasnya Terhadap Larva Udang ( Artemia salina Leach ). Jurnal Ilmu Kefarmasian Indonesia. 16 (2) : 145-149.

Liu WJH. 2011. Traditional Herbal Medicine Reasearch Method. Wiley.

Mukhriani. 2014. Ekstraksi, Pemisahan senyawa, dan Identifikasi Senyawa Aktif. Jurnal Kesehatan. VII (2): 361 367.https://doi.org/10.24817/jkk.v32i2. 2728.

Nassur RCMR., Eduardo VBVB, Francisco VR. 2017. Black garlic: transformation effects, characterization and consumer purchase intention. Comunicata Scientiae. 8 (3): 444 $-451$.

Nurcholis W, Khumaida N, Syukur M, Bintang M. 2017. Evaluation of free radical scavenging activity of ethanolic extract from promising accesions of Curcuma aeruginosa RoxB. Molekul. 12 (2): 133 - 138.

Sa'adah H, Nurhasnawati H, Permatasari V. 2017. Pengaruh Metode Ekstraksi terhadap Kadar Flavonoid Etanol Ekstak Umbi Bawang Dayak (Eleutherine palmifolia ( L .) Merr ) dengan Metode Spektrofotometri. Borneo Journal of Pharmascientech. 01 (01) : 1 - 9.

Saifudin A. 2012. Senyawa Alam Metabolit Sekunder. Deepublish, Yogyakarta.

Shah PM, Priya VP, Gayathri R. 2016. Quercetine - A flavonoid : A Systematic Review. J. Pharm. Sci. \& Res. 8 (8) : 878 880.

Tanaya V, Retnowati R, Suratmo. 2015. Fraksi Semi Polar dari Daun Mangga Kasturi (Mangifera casturi Kosterm). Kimia Student Journal. 1 (1) : 778 - 784.

Wu T, Liu R, Sui W, Zhang M, Guo J, Yang G. 2018. Effects of Incorporation of Black Garlic on Rheological, Textural and Sensory Properties of Rye ( Secale cereale L.) Flour Noodles. CyTA - Journal of Food. 16 (1): 1102 - 1108. https://doi.org/10.1080/19476337.201 8.1515792.

Yuan H, Sun L, Chen M, Wang J. 2016. The comparison of the contents of sugar, Amadori, and Heyns compounds in fresh and black garlic. J Food Sci. 81 (C) : 1662 1668.

Zhafira, R. 2018. Pengaruh lama aging terhadap sifat fisik, kimia, dan aktivitas antioksidan produk bawang hitam lanang. Jurnal Pangan dan Agroindustri. 6 (1) : 34 $-42$.

Zhang X, Li N, Lu X, Liu P, and Qiao X. 2015. Effects of temperature on the quality of black garlic. J Sci Food Agric. 96 : 2366 2372. 
Zuhra CF, Tarigan J, Sitohang H. 2008. Aktivitas antioksidan senyawa flavonoid dari daun katuk (Sauropus androgynus (L) Merr.). Jurnal Biologi Sumatera. ISSN: $1907-5537,3$ (1) : 7 - 1. 